\title{
A formação de uma professora do ensino fundamental: contribuições da Psicologia sócio-histórica
}

\author{
Formação de professor \\ Wanda Maria Junqueira de Aguiar \\ Júlio Ribeiro Soares
}

\begin{abstract}
Resumo
O objetivo deste trabalho é discutir os sentidos e significados de uma professora do ensino fundamental acerca da sua formação em serviço. Metodologicamente, utilizou-se a proposta de núcleos de significação, cujo processo de apreensão de sentidos e significados ocorre por meio da sistematização de pré-indicadores, indicadores e núcleos de significação. Utilizaram-se entrevistas recorrentes com base na fala e em fontes documentais do sujeito. Analisou-se apenas a mediação afetiva na constituição do ser professora. Esse revela aspectos da formação do sujeito articulados à sua docência e ao seu modo de ser professora.

Palavras-Chave: Psicologia; formação de professor; ensino fundamental.
\end{abstract}

\section{The preparation of a basic school teacher: contributions of the social-historical approach in Psychology}

\begin{abstract}
The goal of this study is to discuss the meanings attributed by a basic schooling teacher to her own in-service training. The method employed was the one proposed usually know as "signification centers construction", which tries to grasp the meanings attributed to facts, events and/or situations by focused individuals or groups, through a systematic elaboration of 'pre-indicators', 'indicators' and 'signification centers'. Recurrent interviews and analysis of the subject's available documents. In this paper, however, only one of these centers is fully explained - affective mediation and its role in the process of becoming a teacher. That it allowed a better understanding about how the teacher articulated her training to her practice, i. e, to her way of acting as a teacher.
\end{abstract}

Keywords: Psychology; teacher education; basic school.

\section{La formación de una profesora de la enseñanza primaria: contribuciones de la Psicología socio-histórica}

\section{Resumen}

El objetivo de este trabajo es discutir los sentidos y significados de una profesora de la enseñanza primaria sobre su formación en servicio. Metodológicamente se utilizó la propuesta de núcleos de significado, cuyo proceso de aprehensión de sentidos y significados ocurre por medio de la sistematización de pre-indicadores, indicadores y núcleos de significado. Se utilizaron entrevistas recurrentes con base en el habla y en fuentes documentales del sujeto. Se analizó apenas la mediación afectiva en la constitución del ser profesora. Eso revela aspectos de la formación del sujeto articulados a su docencia y a su modo de ser como profesora.

Palabras clave: Psicología; formación del profesor; enseñanza primaria. 
Este trabalho cujo objetivo geral consiste em discutir os sentidos e significados produzidos por uma professora do ensino fundamental acerca da sua formação acadêmica, tem como base teóricometodológica a Psicologia Sócio-Histórica. Tratase, portanto, de um trabalho cujo método busca revelar o fenômeno em estudo para além do empírico, da imediaticidade que marca a relação sujeito/objeto no mundo concreto. Assim sendo, este trabalho está voltado, essencialmente, para o estudo de particularidades vividas por esse sujeito no processo de sua formação em pedagogia como professora do ensino fundamental.

Para efeito didático, o trabalho foi dividido em três partes: Introdução ao Estudo dos Sentidos e Significados, Método e Uma Aproximação às Zonas de Significações.

\section{Introdução ao estudo dos sentidos e significados}

Para iniciar esta discussão acerca dos sentidos e significados, convém esclarecer antes, o ponto de partida da análise de alguns elementos teóricos. Assim, neste aspecto, partiu-se da concepção sóciohistórica de homem, passando-se pela análise das categorias mediação, pensamento e linguagem e concluiu-se com a análise do processo de constituição dos sentidos e significados na perspectiva sócio-histórica.

Iniciada, assim, a discussão deste trabalho, indaga-se acerca do que seja o homem. Com base nos pressupostos teóricos da Psicologia SócioHistórica, pode-se afirmar que se trata de um ser histórica e socialmente determinado. Trata-se, então, de um ser concreto. Por isso, é um ser que se revela tanto na dimensão social como na dimensão individual, ao mesmo tempo, sem se diluir em nenhuma delas.

Assim, não reduzido à dimensão individual nem à social, o homem é um "ser ativo, social e histórico" (Aguiar, 2001, p.100). Ao agir e transformar o meio no qual atua, o homem transforma a si mesmo, objetivando-se/apropriandose das características culturais da humanidade (Duarte, 1993).

Esse processo de objetivação/apropriação não ocorre, entretanto, de modo direto. São as mediações presentes nos diferentes espaços sociais de atuação do sujeito que o possibilitam. É na apreensão dos diferentes processos de mediação que se encontram os fundamentos explicativos da objetivação/apropriação dos elementos que constituem as características tipicamente humanas, isto é, os elementos que constituem as funções psicológicas superiores do homem (Vygotsky, 1991).

A categoria mediação não tem, portanto a função de apenas ligar a singularidade e a universalidade, mas de ser o centro organizador objetivo dessa relação. Ao utilizarmos a categoria mediação, possibilitamos a utilização, a intervenção de um elemento/um processo, em uma relação que antes era vista como direta, permitindo-nos pensar em objetos/processos ausentes até então (Aguiar \& Ozella, 2006, p. 225).

Ao discutir a existência humana como um processo histórico, destacando a prática como a substância do existir, Severino (2005) também traz uma grande contribuição ao entendimento da categoria mediação. Para o autor, o processo de 
mediação configura-se como práxis, ou seja, como um "movimento que articula dialeticamente a operação e a reflexão, a teoria e a prática" (Severino, 2005, p. 46).

É pela apropriação de particularidades históricas, um processo mediado especialmente pela linguagem, que ocorre o desenvolvimento das funções psicológicas superiores. Este processo significa, segundo Vygotsky (1991), “a reconstrução interna de uma operação externa" (p. 63). Significa, portanto, que o desenvolvimento das funções superiores do psiquismo se processa a partir das relações do sujeito com os "sistemas de signos produzidos socialmente, o que nos leva a concluir que as mudanças individuais têm origem na sociedade, na cultura, mediadas pela linguagem" (Aguiar, 2001, p. 102).

Ao se compreender o modo pelo qual as funções do psiquismo são mediadas, de modo que propiciam o seu desenvolvimento, o estudo das relações pensamento e linguagem é um dos mais importantes para a Psicologia.

De acordo com Vigotski (2001), as relações entre pensamento e linguagem "surgem e se constituem unicamente no processo do desenvolvimento histórico da consciência humana, sendo, elas próprias, um produto e não uma premissa da formação do homem" (p. 395). Convém assinalar, com isso, que é na relação homem/mundo, relação essa que é sempre mediada por processos significados, que o pensamento e a linguagem se constituem como síntese de muitas determinações de significados apreendidos pelo indivíduo a partir de sua vivência no mundo. A relação pensamento e linguagem se configura, então, como unidade do diverso cuja materialidade é a palavra significada.

É pela mediação dos processos significados, portanto, que são gerados os espaços de inteligibilidade na constituição dessa unidade (pensamento e linguagem). Nesse sentido, o significado não é apenas parte constitutiva do discurso. É, também, do pensamento. Assim, “para compreender a fala de alguém, não basta entender suas palavras; é preciso compreender seu pensamento (que é sempre emocionado), é preciso apreender o significado da fala" (Aguiar, 2001, p. 130). Convém ressaltar, contudo, que a unidade pensamento/linguagem não nega a singularidade de nenhuma dessas duas zonas do psiquismo. Entretanto, ao mesmo tempo que o pensamento não é a linguagem, e vice-versa, dialeticamente nenhuma dessas zonas do psiquismo se constitui sem a outra.

A apropriação da linguagem contribui não apenas para que o homem desenvolva sua capacidade de comunicação. Ao mesmo tempo em que a linguagem faz da comunicação uma atividade humana, ou seja, uma atividade mediada pelo discurso significado, o qual constitui a unidade pensamento/linguagem, ela propicia, também, o desenvolvimento da consciência do sujeito. É pela palavra, portanto, que se apreende o modo de "ser, pensar e agir do sujeito" (Aguiar \& Ozella, 2006, p. 226).

Os significados das palavras, contudo, não são estáticos. Pelo contrário, são dinâmicos e se desenvolvem. Com isso, modificam também a relação do pensamento com a palavra. Nesse sentido, toda essa relação que tem como elemento mediador a palavra carregada de significado, 
configura-se como um processo dinâmico, em pleno desenvolvimento.

Além de dinâmica, a relação pensamento/ linguagem é, também, complexa e até contraditória. Assim, nem sempre o ato do pensamento coincide com a própria fala. Quantas vezes, por exemplo, tentando dizer algo que se pensa e não se consegue ou se diz isto de um modo totalmente diferente do que realmente pensamos? Isso, contudo, não nega a tese segundo a qual "ao transformar-se em linguagem, o pensamento se reestrutura e se modifica" (Vigotski, 2001, p. 412). Dessa forma, compreendemos que o pensamento, por conta da totalidade que o constitui, não se expressa na palavra, mas nela se realiza.

A relação pensamento/linguagem também não se reduz à dimensão simbólica e cognitiva. $\mathrm{O}$ pensamento, como um processo de sentido, está implicado sempre pelas significações e emoções que constituem o sujeito.

Ao compreenderem o pensamento como um processo, algo sempre emocionado, Aguiar e Ozella (2006, p. 226) analisam a relação pensamento/linguagem a partir da mediação que a constitui: "a transição do pensamento para a palavra passa pelo significado e o sentido". Dessa forma, a compreensão de um pensamento implica, necessariamente, a compreensão das significações ${ }^{2}$ que o constituem.

No estudo da relação pensamento/linguagem, sentidos e significados são, portanto, categorias centrais para se compreender a relação homem/mundo. Relação esta que é sempre significada pelas mediações simbólicas e afetivas. Conforme afirma Pino (2005, p. 55), "é a significação que tem o poder de converter o fato natural em fato cultural e, dessa maneira, permite a passagem do plano social para o pessoal".

A relação do sujeito com o mundo, compreendida como um processo de apropriação da realidade, não transforma apenas o mundo externo. Ao agir sobre o mundo, o sujeito apreende o significado de suas ações, o que o faz articular, sempre, novas significações. Essas novas significações articuladas transformam o sujeito, modificando-o internamente.

As significações são sempre dinâmicas e se desenvolvem na relação do homem com o mundo, do pensamento com a palavra. Dessa forma, significações já existentes se modificam a partir da apropriação de novas significações (processo de articulação de novas significações). Assim, é a partir do conhecimento da dinâmica das significações que se pode compreender a mobilidade do pensamento, isto é, os significados e os sentidos que o constituem.

Do ponto de vista psicológico, os significados são sempre "produções históricas e sociais. São eles que permitem a comunicação, a socialização de nossas experiências" (Aguiar \& Ozella, 2006, p. 226). Os significados, na realização do pensamento discursivo, configuram-se como uma possibilidade de comunicação mais universal; são compartilhados de modo mais equiitativo nas situações comunicativas porque sua origem é convencional.

Compreendidos como produções históricas e sociais, os significados se constituem pelas marcas da afirmação e da contradição. Assim, a estabilidade dos significados não é fixa, irredutível. Ao mesmo tempo que se afirmam como estáveis, os significados se modificam e superam suas características relacionais com o pensamento. 
Significados e sentidos não são apenas duas categorias diferentes, são, também, complementares. Os sentidos, entretanto, não se reduzem aos significados. Do ponto de vista psicológico, os sentidos são muito mais amplos que os significados, pois, pela sua mobilidade, aqueles são eixos sobre os quais se articulam os "eventos psicológicos que o sujeito produz frente uma realidade" (Aguiar \& Ozella, p. 226-227).

Vigotski (2001) afirma que "o sentido é sempre uma formação dinâmica, fluida, complexa, que tem várias zonas de estabilidade variada" (p. 465). Com relação à categoria significado, tece o comentário de que "o significado é apenas uma dessas zonas de sentido que a palavra adquire no contexto de algum discurso e, ademais, uma zona mais estável, uniforme e exata" (p. 465).

Comparados aos significados, os sentidos são mais singulares, subjetivos. Mais flexíveis, os sentidos variam de acordo com a totalidade da vida do sujeito, de modo que dependem de todas as experiências vividas. Os sentidos estão, assim, mais próximos dos indivíduos. Estão, portanto, mais implicados pela unidade afetivo-cognitiva que constitui o ser humano e sua história de desenvolvimento.

Ao estudar a constituição humana, muitas vezes a dimensão afetiva é esquecida. Assim, o ser humano parece reduzido apenas à dimensão cognitiva. Contudo, o ser humano não é constituído apenas de pensamento e linguagem. "A emoção é uma condição permanente na definição do sujeito. A linguagem e o pensamento se expressam a partir do estado emocional de quem fala e pensa" (González Rey, 2003, p. 236).
$\mathrm{Na}$ busca de compreensão do homem, considerando a totalidade física e psíquica que o constitui, ou seja, sua condição cognitiva, afetiva e biológica, Aguiar e Ozella (2006) apontam que a separação entre pensamento e afeto não pode ser feita. Caso ocorra, corre-se o "risco de fechar-se definitivamente o caminho para a explicação das causas do próprio pensamento, pois a análise do pensamento pressupõe necessariamente a revelação dos motivos, necessidades e interesses que orientam o seu movimento" (p. 227).

Deste modo, a compreensão do pensamento de alguém não depende apenas da compreensão do seu discurso, mas dos seus verdadeiros motivos, que são, sempre, afetivos e volitivos. Na perspectiva de superação da dicotomia afeto/cognição, duas categorias têm sido estudadas por Aguiar e Ozella (2006): as necessidades e os motivos. O estudo dessas categorias muito tem contribuído para a compreensão do processo da produção de sentidos e significados pelos sujeitos nos espaços de suas relações sociais.

As necessidades humanas não se reduzem a determinações biológicas ou sociais da existência humana. As necessidades, pela concepção aqui enfatizada, constituem-se a partir da articulação entre as dimensões biológica, social e histórica do indivíduo. Nesse sentido, "o que possibilita o desenvolvimento histórico é justamente o fato de que a apropriação de um objeto [...] gera, na atividade e na consciência do homem, novas necessidades e novas forças, faculdades e capacidades" ${ }^{10}$ (Duarte, 1993, p. 35).

\footnotetext{
${ }^{3}$ Grifos do autor.
} 
Não são apenas as necessidades biológicas que se transformam em necessidades sociais. Estas também se transformam em novas necessidades, que também são sociais, isto é, necessidades propriamente humanas. Essas necessidades funcionam como uma força que gera, sempre, novas necessidades. Esse processo, que já não está colado às necessidades biológicas, é histórico; ele é, portanto, infinito, inesgotável.

As necessidades, assim como as emoções, não podem ser descoladas do processo cultural e histórico que constitui o sujeito em sua singularidade.

As necessidades são entendidas como um estado de carência do indivíduo que leva a sua ativação com vistas a sua satisfação, dependendo das suas condições de existência. Temos assim, que as necessidades se constituem e se revelam a partir de um processo de configuração das relações sociais, processo este que é único, singular, subjetivo e histórico ao mesmo tempo. Além disso, é fundamental ressaltar que, pelas características do processo de configuração, o sujeito não necessariamente tem o controle e, muitas vezes, a consciência do movimento de constituição das suas necessidades. Assim, tal processo só pode ser entendido como fruto de um tipo específico de registro cognitivo e emocional, ou seja, a constituição das necessidades se dá de forma não intencional, tendo nas emoções um componente fundamental. (Aguiar \& Ozella, 2006, p. 228).

As necessidades se configuram, portanto, a partir do modo pelo qual se amplia o processo de participação do sujeito nos espaços sociais que o constituem. Dessa forma, elas estão relacionadas ao modo pelo qual o sujeito pensa, sente e age ante à complexidade de novos espaços, mesmo que esse processo de atuação (pensar, sentir e agir) ocorra de modo não consciente e não intencional.

Assim, por exemplo, ao ser transferido para uma nova escola, onde a proposta pedagógica, os alunos e os colegas de trabalho são diferentes em relação a escola antiga, um professor pode passar por um processo de construção de novas necessidades. Esse processo, contudo, nem sempre é tranqüilo, harmonioso. Ao contrário, pode ser marcado por muitos conflitos e, possivelmente, essas novas necessidades o impulsionarão para a busca de satisfação, fato que só ocorrerá quando significar os motivos que direcionarão sua ação. Aguiar e Ozella (2006, p. 228) esclarecem que esse "processo, de ação do sujeito no mundo a partir das suas necessidades, só vai se completar quando o sujeito significar algo do mundo social como possível de satisfazer suas necessidades".

Como apontado no exemplo anterior, um professor, ao ser transferido para uma nova escola, pode passar por um processo de construção de novos sentidos. Assim sendo, ele se mobilizará para satisfazer as novas necessidades gestadas nesse novo espaço e suas ações se orientarão pelos novos motivos significados à luz da nova realidade.

Com isso, convém salientar que os motivos só se constituem quando fenômenos da realidade são significados pelo sujeito como capazes de atender às suas necessidades. Assim, no momento em que novas necessidades são satisfeitas, novos motivos se constituem para a ação e novos sentidos se configuram.

A possibilidade de realizar uma atividade, que vá na direção da satisfação das necessidades, com certeza modifica o sujeito, criando novas 
necessidades e novas formas de atividade. Afirmase, assim, que a necessidade não conhece seu objeto de satisfação, ela completa sua função quando o 'descobre' na realidade social. Entende-se que este movimento se define como a configuração das necessidades em motivos. Com isso, se diz que os motivos se constituirão como tal somente no encontro com o sujeito, no momento que o sujeito o configurar como possível de satisfazer as suas necessidades. (Aguiar \& Ozella, 2006, p. 228)

Os motivos, aqui compreendidos não como sistemas naturalmente intrapsíquicos, são constituídos a partir da integração de elementos de sentidos produzidos em diferentes espaços sociais de atuação do sujeito. Assim, os motivos estão associados aos sentidos, os quais se constituem a partir da unidade entre a dimensão simbólica e a dimensão afetiva na constituição do sujeito.

Acerca do modo pelo qual se compreende o papel do motivo na constituição do humano, Vigotski (2001) comenta que o "pensamento não nasce de outro pensamento, mas do campo da nossa consciência que o motiva, que abrange os nossos pendores e necessidades, os nossos interesses e motivações, os nossos afetos e emoções" (p. 479).

Os motivos são elementos subjetivos profundamente implicados pela microgênese do sujeito, pela singularidade que o constitui na relação com o mundo; implicados, enfim, pela história da mediação afetiva dos sujeitos. Dessa forma, os motivos estão sempre relacionados à produção de novos sentidos pelo sujeito no espaço de suas relações sociais.

\section{Método}

Dada a proximidade dos autores com o curso de Pedagogia ofertado pelo Programa Especial de Formação Profissional para a Educação Básica (PROFORMAÇÃO) da Universidade do Estado do Rio Grande do Norte (UERN) e o interesse pelo estudo da formação do professor em serviço, fez-se opção por sujeitos que fossem alunos egressos desse curso. Como isso aconteceu? Atendendo ao pedido dos autores, uma professora de estágio supervisionado do referido curso indicou dez alunos egressos que haviam se destacado de modo excelente na formação. Dentre esses, três se mostraram disponíveis e muito interessados em participar da pesquisa.

Para a realização da primeira entrevista, solicitou-se, então, que os três sujeitos lessem o terceiro capítulo ${ }^{4}$ de seus memoriais de formação e destacassem os pontos que consideram mais interessantes, aqueles que os fazem refletir, de alguma forma, acerca de algumas questões, como sua formação acadêmica, seus alunos, seu trabalho docente.

De posse dos dados, fez-se uma primeira leitura do material redigido pelos sujeitos, o que nos permitiu apreender alguns aspectos da realidade constitutiva da formação. Dada a necessidade de aprofundamento da análise do fenômeno em estudo, optou-se por trabalhar não mais com três, e sim um sujeito apenas. Fez-se opção por aquele que melhor conseguia elaborar e expressar suas opiniões acerca da formação.

De modo sintético, pode-se afirmar que o sujeito de pesquisa é do sexo feminino, morou na zona 
rural até os seis anos de idade, passou muitas dificuldades escolares no início de sua escolarização e exerce o magistério há pouco mais de dez anos. Atualmente é casado e tem pouco mais de trinta anos de idade. A esse sujeito, que é professora do ensino fundamental, lhe foi atribuído o codinome de Raquel.

Em conformidade com Aguiar e Ozella (2006), a primeira etapa do processo de análise consistiu na seleção de pré-indicadores, cuja intenção não foi analisar as narrativas do sujeito, mas apreender a totalidade dos dados. Assim, partiu-se das "palavras inseridas no contexto que lhe atribui significado, entendendo aqui como contexto desde a narrativa do sujeito até as condições histórico-sociais que o constitui" (idem, pp. 229-230).

A segunda etapa consistiu num processo aglutinador de pré-indicadores em indicadores e seus conteúdos. Os autores acima (2006) destacam que é esse processo que permite "caminhar na direção dos possíveis núcleos de significação" (p. 230).

Constituídos os indicadores e seus conteúdos temáticos, meio pelo qual foram inferidos $\mathrm{e}$ sistematizados os núcleos de significação, - terceira etapa - passou-se para uma nova etapa da pesquisa, mais complexa e profunda, cuja finalidade consistiu em superar o nível de descrição empírica (aparência) e atingir o nível interpretativo dos dados (essência).

\section{Uma aproximação às zonas de significações}

Nesta parte, o objetivo consiste em apresentar a análise dos sentidos e significados produzidos pelo sujeito acerca de sua formação acadêmica em serviço. É importante enfatizar, contudo, que a história pessoal e profissional desse sujeito é parte constitutiva dessa análise, de modo que, sem ela, não seria possível apreender as determinações que o constituem em seu processo de formação acadêmica como professora.

$\mathrm{Na}$ análise, leva-se em conta que, "para compreender a fala de alguém, não basta entender suas palavras; é preciso compreender seu pensamento (que é sempre emocionado), é preciso apreender o significado da fala" (Aguiar, 2001, p. 130). Considera-se, portanto, que, para compreender os sentidos e significados produzidos por Raquel acerca de sua formação, faz-se necessário compreender as particularidades que a constituem como sujeito histórico no mundo.

Optou-se por não apresentar a análise dos cinco núcleos. Como forma de exemplificação, foi selecionado apenas um núcleo, aquele que melhor revela aspectos da formação do sujeito articulados à sua docência, ao modo de ser professora: a mediação afetiva na constituição do ser professora.

Com base em Vigotski (2001), que afirma que “a compreensão efetiva e plena do pensamento alheio só se torna possível quando descobrimos a sua eficaz causa profunda afetivo-volitiva" (p. 479480), compreende-se que a apreensão dos sentidos e significados produzidos por Raquel acerca da sua 
formação acadêmica, só se torna possível a partir da análise das mediações afetivas que a constituem no curso, sem dispensar, obviamente, a totalidade de sua história de vida. Nessa mesma perspectiva teórica, Aguiar e Ozella (2006) apontam que, "para se avançar na compreensão do homem, ou melhor, dizendo, dos seus sentidos, temos que, nas nossas análises, considerar que todas as expressões humanas são cognitivas e afetivas" (p. 227).

Ao trazer o tema afetividade para discussão, destaca-se que o estudo da mediação afetiva no processo de constituição do humano é algo de fundamental importância para a compreensão do professor nos diversos espaços sociais, sobretudo o educacional. Conforme apontam Leite e Tassoni (2002), a relação do homem com a realidade é algo profundamente implicado pela afetividade.

Raquel afirma que "quando [foi] fazer Pedagogia, [suas] expectativas eram, principalmente, adquirir novos conhecimentos, aprender coisas novas!". Assim sendo, jamais, nesta análise, poder-se-ia deixar o tema afetividade de lado. Leite (2006) aponta que "a afetividade constitui-se como um fator de grande importância na determinação da natureza das relações que se estabelecem entre os sujeitos (alunos) e os demais objetos de conhecimento (áreas e conteúdos escolares), bem como na disposição dos alunos diante das atividades propostas e desenvolvidas" (p. 24).

$\mathrm{Na}$ sua fala, Raquel revela-se atravessada não apenas pela dimensão cognitiva, mas também afetiva. Ao afirmar que tinha expectativas em relação ao curso, revela um sentimento de interesse pelo curso. E complementa: "Eu tinha muita vontade! E eu me empenhei no curso. Acho que me desenvolvi bastante". Ao se constituir como motivo impulsionador das ações de Raquel, não se pode deixar de considerar, portanto, que o curso no qual se formou é parte social constitutiva de si, do seu modo de pensar, sentir e agir não apenas como aluna, mas também como professora.

Ao discutir os sentidos e significados da formação de Raquel, outro elemento vem à tona: os sentidos e significados de ser professora. É esse movimento de articulação de sentidos e significados que permite apreender Raquel afetivamente implicada como aluna e professora ao mesmo tempo.

Conforme observação no decorrer desta análise, Raquel, ao falar de sua formação, traz sempre à tona questões pedagógicas vividas como professora na escola e na sala de aula. Assim sendo, o curso jamais seria o mesmo para Raquel não fosse ela professora. E a professora Raquel jamais seria a mesma não fosse o curso.

De acordo com Leite (2006), analisar a questão da afetividade significa "analisar as condições concretas pelas quais se estabelecem os vínculos entre o sujeito (aluno) e o objeto (conteúdos escolares)" (p. 25). São, pois, determinadas condições concretas, vividas por Raquel como professora, que a vinculam afetivamente à sua formação acadêmica. Dessa forma, somente a análise dessas condições é que permite apreender o modo pelo qual Raquel é atravessada afetivamente pelo curso. Prossegue-se, então, a analisar os sentidos e significados da formação de Raquel de modo articulado aos sentidos e significados de ser professora.

Os sentidos e significados produzidos por Raquel acerca da sua formação se explicitam 
articulados com os sentidos e significados de sua carreira profissional em vários momentos de sua fala, dentre os quais, convém ressaltar: "antes de fazer o curso, tinha certas atitudes que eu tomava com relação aos meus alunos que, hoje, eu vejo que eram erradas". Na verdade Raquel aponta que o curso implicou transformações no seu modo de ser, no seu modo de pensar, sentir e agir como professora.

Um dos pontos destacados por Raquel, ao enfatizar a importância da sua formação acadêmica para a docência, diz respeito à postura pedagógica de seus professores do ensino fundamental e médio. Assim se expressa: "Eu aprendi no método tradicional [...] Hoje não [os] ignoro, mas também não ensino da mesma forma que eles me ensinaram". Para Raquel, na escola tradicional "os professores não davam oportunidade para o aluno falar de suas dificuldades!" Tradicional ou não, o que importa nesta análise são as mediações que configuram o processo escolar de ensino e aprendizagem como afetivas na relação entre professor e aluno.

Aqui, especificamente, será destacada uma questão: dentre vários elementos culturais, o professor é um dos maiores determinantes da qualidade da aprendizagem de seus alunos. Dependendo da mediação do professor em sala de aula, a aprendizagem tanto pode ocorrer ou não, pois é a "qualidade da mediação [que] determina, em grande parte, a qualidade da relação sujeitoobjeto" (Leite \& Tassoni, 2002, 130). No caso, então, de professores que não dialogam com seus alunos, a aprendizagem destes nem sempre poderá indicar bons resultados. Diante de casos assim, podem ser esperadas, inclusive, conseqüências como as declaradas por Raquel: "Eu cheguei a ser reprovada por causa dessa questão de não ter a oportunidade de falar sobre as minhas dificuldades com a professora".

Talvez o mais complicado nos casos de reprovação seja o fato de haver sempre um culpado: $\mathrm{o}$ aluno. E isso acontece porque, segundo algumas teorias pedagógicas e psicológicas, o aluno ou é irresponsável, ou é incapaz, ou tem problema de aprendizagem, ou não tem aptidão, ou ainda não tem prontidão, ou não tem capital cultural, ou..., ou..., ou... Em síntese, pôde-se afirmar que "o mecanismo de pensamento que opera nesta construção é a redução de tudo que é de natureza social a questões individuais" (Aguiar \& Bock, 2003, p. 135). E, assim, muitas vezes, termina-se por estigmatizar muitos alunos.

Considerada, pela escola, uma aluna com dificuldades de aprendizagem, incapaz de aprender o que os professores ensinavam. Raquel, como milhares de outras crianças pobres, também sofreu a humilhação de ser reprovada. Acerca dessa questão, Leite (2006) diz que "decisões de ensino inadequadas dificultam o processo de aprendizagem e as implicações envolvem também as dimensões afetivas, podendo os referidos conteúdos tornaremse aversivos para a vida futura do aluno" (p. 25).

Raquel, contudo, mediada por particularidades do seu mundo social, enfrentou o obstáculo da reprovação e não desistiu dos estudos. Talvez alguma reprovação a mais a tivesse levado a sucumbir diante das "decisões de ensino inadequadas" da escola, tornando-a mais uma vítima a engrossar a fileira dos estigmatizados como sujeitos "incapazes". Não porque ela fosse, de fato, incapaz de aprender; mas porque condições 
sociais e pedagógicas postas poderiam implicar-lhe na construção dessa imagem acerca de si mesma.

Ao falar de sua condição de aluna, Raquel não deixa de falar de sua condição de professora. Saber reconhecer o aluno na sua condição social é uma questão sobre a qual ela atribui muita importância na sua formação como professora. "Eu considero que meus alunos têm objetivos, e eu tenho a obrigação de procurar saber o que eles sabem, o que eles têm vontade e necessidade de conhecer, para que eu possa partir disso, desenvolver minhas aulas a partir disso, o que eles precisam aprender".

Próxima dos alunos, Raquel revela-se afetivamente atravessada pela condição de ser professora. Conforme afirma González Rey (2003, p. 242), "a emoção caracteriza o estado do sujeito ante toda ação, ou seja, as emoções estão estreitamente associadas às ações por meio das quais caracterizam o sujeito no espaço de suas relações sociais". Assim sendo, Raquel revela-se afetivamente implicada nas suas ações como aluna e professora.

Ao afirmar: "muita coisa que eu fiz, no início da minha carreira docente, se eu soubesse eu não teria feito", Raquel explicita a condição de ter se transformado a partir do curso. Dessa forma, podemos afirmar que o curso contribuiu para que ela construísse novas significações acerca do modo de ser professora.

O novo e o velho se encontram constituindo Raquel como ser histórico, um ser em movimento e ação; um ser, em síntese, que vivencia processos de mudanças no seu modo de ser no mundo. Daí, o fundamento da afirmação de que o curso imprimiu mudanças em seu modo de compreender o mundo e nele agir: "Percebo que a minha prática é muito diferente da prática de antigamente!".

Pôde-se afirmar, deste modo, que a forma de ser professora, expressa por Raquel, foi dialética e historicamente constituída. A partir do curso, Raquel expressa o seguinte pensamento acerca de si: "Eu me sinto, hoje, não só uma professora diferente, mas uma pessoa diferente!". Ser professora, para Raquel, é uma ação significada no mundo e para o mundo. É, portanto, uma ação que a motiva, que a satisfaz como sujeito historicamente constituído na relação com a escola, com os alunos, com o mundo, consigo mesma. É pela mediação afetiva da docência, portanto, que se pode aproximar da compreensão dos sentidos constitutivos da formação de Raquel.

\section{Discussão}

Considerando que a Psicologia Sócio-Histórica pode contribuir profundamente, a partir de seu método e suas categorias teóricas, para a explicação do processo educativo, ocorre uma ajuda para se pensar, inclusive, a formação de professores a partir das forças que a constituem, de suas determinações, de modo que pode explicitar o real que configura as práticas educativas dos professores na escola e outras questões mais, como relação entre professores e alunos, seleção de conteúdos escolares e sua ideologia subjacente, dificuldades vividas por professores e alunos no âmbito escolar.

Este trabalho, cuja base teórico-metodológica é a Psicologia Sócio-Histórica, traz dados de uma pesquisa realizada com apenas um sujeito, uma professora do ensino fundamental de uma cidade do 
interior do Rio Grande do Norte. O fato de essa pesquisa ter sido realizada com apenas um sujeito não invalida, contudo, a possibilidade de generalização dos resultados obtidos. No entanto, dada a perspectiva teórica e metodológica adotada, é necessário destacar como generalização o que está aqui sendo compreendido. No caso, de modo algum, refere-se à possibilidade de estender os resultados desta pesquisa para todos os sujeitos que vivam situações semelhantes.

Para a perspectiva adotada cada pessoa, ao vivenciar determinadas situações particulares, sociais e históricas, que são mediadoras da sua subjetividade, torna-se única em sua singularidade. No entanto, não se pode deixar de lembrar que o social se revela no individual e vice-versa. Dialeticamente, o social (todo) não é, portanto, uma soma de indivíduos (partes). Um faz parte da constituição do outro, negando-o, afirmando-o, complementando-o.

O social não é apenas algo externo ao sujeito, mas parte constitutiva deste. Assim sendo, também é possível afirmar que o individual não é algo exclusivo do sujeito. Ele se revela no social. O homem é, assim, um ser singular e universal ao mesmo tempo; um ser que é único, mas que tem encarnado em si o mundo social com o qual se relaciona.

Os dados de uma pesquisa que tenha sido realizada com apenas um sujeito, como a que ora se apresenta não invalidam, portanto, a possibilidade de generalização de seus resultados. Dessa forma, Raquel, o sujeito de pesquisa, não revela apenas a singularidade de um sujeito, mas um mundo que também é parte constitutiva de muitos outros professores que passaram por um processo de formação semelhante.

Raquel é única na forma de significar a sua formação acadêmica, mas é também, ao mesmo tempo, reveladora da universalidade do curso que mediou a formação de vários outros professores. Considerando, portanto, que a parte é reveladora do todo, ao se falar de Raquel não se refere apenas a uma pessoa, mas a uma universalidade que é parte constitutiva de ser.

Além destas considerações, metodologicamente é importante agregar outro aspecto que completa esta visão sobre o que vem a ser a capacidade de generalização de uma pesquisa, ou seja, o potencial de produção de conhecimento de uma investigação. Entende-se que a análise e a conseqüente teorização realizada sobre a realidade pesquisada produzem um conhecimento que pode iluminar, desvelar e produzir uma nova realidade, talvez mais complexa e reveladora das contradições. Afirma-se, assim, que a teorização sobre a realidade, que especificamente as pesquisas qualitativas alcançam, é produção de conhecimento que potencialmente se estende a outras realidades investigadas, ou, em outras palavras, pode ser generalizada.

Ao passar por um processo de formação acadêmica em serviço, conforme vivenciou Raquel, o professor pode ser implicado profundamente, isto é, pode gestar novas necessidades diante da realidade educacional com a qual sempre conviveu. Pode, em síntese, re-significar sua forma de agir, pensar e sentir o processo educativo.

Assim sendo, uma formação dessa natureza pode contribuir para que o professor extrapole seu cotidiano imediato; ou, como aponta Heller (1989), pode contribuir para que extrapole "o caráter 
momentâneo dos efeitos, a natureza efêmera das motivações e, a fixação repetitiva do ritmo, a rigidez do modo de vida" (p. 43).

Melhorar a prática pedagógica para que pudesse atender mais competentemente seu aluno a partir das dificuldades apresentadas é uma fala recorrente de Raquel. Talvez, como hipótese, é possível afirmar que, ao não se isolar dos outros professores, da realidade social que a constitui, do que Clot (2006) denomina gênero, Raquel revele intenções e necessidades comuns a muitos professores.

Ao fazerem um curso, professores podem, sim, pensar em mudança no seu modo pedagógico de ser, o que significa a pressuposição de atuarem numa perspectiva de "transformação dos homens, modificando as formas de relações entre eles, contribuindo para a superação, em sua consciência, dos seus fundamentos ideológicos" (p. 88).

Para muitos professores, assim como foi para Raquel, uma formação acadêmica, portanto, pode significar possibilidade de transformação e construção de um novo modo de pensar, sentir e agir, o que se configura como motivo mobilizador de novas ações. Para isso, faz-se necessário que essa formação implique o sentido de que todo processo educativo deve ser um processo de humanização, ou seja, uma atividade não alienada, mas compromissada com o processo histórico de transformação das condições objetivas com as quais os professores se relacionam, com a transformação de seus alunos, que também são sujeitos histórica e socialmente determinados.

\section{Referências}

Aguiar, W. M. J. (2001). Consciência e Atividade: categorias fundamentais da psicologia sócio-histórica. Em A. M. B. Bock, O. Furtado \& M. G. Gonçalves (Orgs.), Psicologia Sócio-Histórica: uma perspectiva crítica em psicologia (pp. 95-110). São Paulo: Cortez.

Aguiar, W. M. J. (2001). A Pesquisa em Psicologia Sócio-Histórica: contribuições para o debate metodológico. Em A. M. B. Bock, O. Furtado \& M. G. Gonçalves (Orgs.), Psicologia Sócio-Histórica: uma perspectiva crítica em psicologia (pp. 129-140). São Paulo: Cortez.

Aguiar, W. M. J., \& Bock, A. M. B. (2003). Psicologia da Educação: em busca de uma leitura crítica e de uma atuação compromissada. Em: A. M. B. Bock, O. Furtado \& M. G. Gonçalves (Orgs.), A Perspectiva SócioHistórica na Formação em Psicologia (pp. 132-160). Petrópolis, RJ: Vozes.

Aguiar, W. M. J., \& Ozella, S. (2006). Núcleos de Significação Como Instrumento para a Apreensão da Constituição dos Sentidos. Psicologia: Ciência $e$ Profissão, 26(2), 222-245.

Clot, Y. (2006). A Função Psicológica do Trabalho. Petrópolis, RJ: Vozes.

Duarte, N. (1993). A individualidade para-si: contribuição a uma teoria histórico-social da formação do indivíduo. Campinas, SP: Autores Associados.

González Rey, F. L. (2003). Sujeito e Subjetividade: uma aproximação histórico-cultural. São Paulo: Thomson. Heller, A. (1989). O Cotidiano e a História. Rio de Janeiro: Paz e Terra.

Leite, S. A. S. (2006). Afetividade e Práticas Pedagógicas. Em S. A. S. Leite (Org.), Afetividade e 
Práticas Pedagógicas (pp. 15-45). São Paulo: Casa do Psicólogo.

Leite, S. A. S., \& Tassoni, E. C. M. (2002). A Afetividade em Sala de Aula: as condições de ensino e a mediação do professor. Em R. Azzi \& A. M. Sadalla (Orgs.), Psicologia e Formação Docente: desafios e conversas (pp. 113-141). São Paulo: Casa do Psicólogo.

Pino, A. (2005). A Psicologia Concreta de Vigotski: implicações para a educação. Em V. M. N. S. Placco
(Org.), Psicologia \& Educação: revendo contribuições (pp. 33-61). São Paulo: EDUC.

Severino, A. J. (2005). Educação, Sujeito e História. São Paulo: Olho d'Água.

Vygotsky, L. S. (1991). A Formação Social da Mente: o desenvolvimento dos processos psicológicos superiores. São Paulo: Martins Fontes.

Vigotski, L. S. (2001). A Construção do Pensamento e da Linguagem. São Paulo: Martins Fontes.

Recebido em: 01/10/2007

Revisado em: 09/07/2008

Aprovado em: 04/08/2008

Sobre os autores:

Wanda Maria Junqueira de Aguiar (iajunqueira@uol.com.br) - Professora do Programa de Estudos Pós-Graduados em Educação: Psicologia da Educação da Pontifícia Universidade Católica de São Paulo

Júlio Ribeiro Soares (jjjrib@uol.com.br) - Doutorando em Educação: Psicologia da Educação pela Pontifícia Universidade Católica de São Paulo 